\title{
Stem cells, niche, and zones
}

\author{
Linheng $\mathrm{Li}^{1}$ \\ ${ }^{1}$ Stowers Institute for Medical Research
}

It is a fundamental question regarding how to keep the balance between long term maintenance of stem cells and meanwhile supporting active tissue regeneration. The stem cell niche plays an essential role in maintenance and regulation of stem cells. In mammals, however, keep stem cells as quiescent is an important mechanism for long term maintenance of stem cells. How to fulfill these two tasks simultaneously is a challenge. Here we will discuss our recent concept of separate zones for maintenance and expansion of stem cells in organisms with long life span.

Keywords: stem cell, niche, stem cell regulation

Cell Research (2008) 18:s91. doi: 10.1038/cr.2008.181; published online 4 August 2008

Linheng Li, PhD, Associate Investigator, Stowers Institute for Medical Research Linheng Li graduated from Fudan University in 1985 with a BS in Biology and continued his graduate studies at the Genetics Institute of Fudan University under the supervision of Dr Shou-yuan Zhao. He received both his M.S. (1993) and PhD degrees (1995) from the New York University Medical Center in New York mentored by Dr Edward Ziff. From 1995-1999 Linheng was a postdoctoral fellow in the laboratory of Dr Leroy Hood. Linheng Li opened his own laboratory at the Stowers Institute for Medical Research in Kansas City, Missouri in the fall of 2000. He currently holds the position of Associate Investigator at Stowers and of Affiliate Associate Professor in the Division of Cancer \& Developmental Biology of the Department of Pathology at the University of Kansas
Medical Center. Linheng Li research investigates the molecular and cellular mechanisms that regulate adult stem cell development in the hematopoietic and intestinal tissues. He is currently interested in investigating of the roles of the BMP, Wnt, and PTEN-Akt signal pathways in regulation of stem cell development. Specific study areas include: 1) how the microenvironment (niche) maintains adult stem cells, controls stem cell number, and regulates stem cell properties including self-renewal, during homeostasis, and 2) how cancer stem cells arise to initiate tumorigenesis. Linheng received the 2003 Missouri Biotechnology Association Excellence in Life Sciences Award in Basic Research and the 2004 Hudson Prize for excellence in basic biomedical research. 